Article

\title{
Environmental Assessment of Latent Heat Thermal Energy Storage Technology System with Phase Change Material for Domestic Heating Applications
}

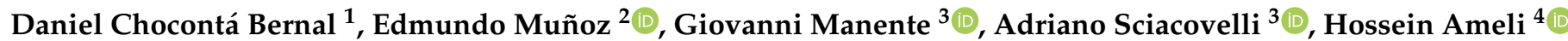 \\ and Alejandro Gallego-Schmid ${ }^{5, *}$ \\ 1 Pariser Building, School of Mechanical, Aerospace and Civil Engineering, The University of Manchester \\ Sackville Street, Manchester M13 9PL, UK; Daniel.chocontabernal@postgrad.manchester.ac.uk \\ 2 Center for Sustainability Research, Universidad Andres Bello, República 440, Santiago 8370251, Chile; \\ edmundo.munoz@unab.cl \\ 3 Birmingham Centre for Energy Storage, School of Chemical Engineering, University of Birmingham, \\ Edgbaston, Birmingham B15 2TT, UK; G.Manente@bham.ac.uk (G.M.); a.sciacovelli@bham.ac.uk (A.S.) \\ 4 Department of Electrical and Electronic Engineering, Imperial College London, Exhibition Rd, South \\ Kensington, London SW7 2BU, UK; h.ameli14@imperial.ac.uk \\ 5 Pariser Building, Tyndall Centre for Climate Change Research, School of Mechanical, Aerospace and Civil \\ Engineering, The University of Manchester, Sackville Street, Manchester M13 9PL, UK \\ * Correspondence: alejandro.gallegoschmid@manchester.ac.uk
}

Citation: Chocontá Bernal, D.;

Muñoz, E.; Manente, G.;

Sciacovelli, A.; Ameli, H.;

Gallego-Schmid, A. Environmental

Assessment of Latent Heat Thermal

Energy Storage Technology System

with Phase Change Material for

Domestic Heating Applications.

Sustainability 2021, 13, 11265. https://

doi.org/10.3390/su132011265

Academic Editors: Fausto Cavallaro and Valeria Palomba

Received: 1 September 2021

Accepted: 7 October 2021

Published: 13 October 2021

Publisher's Note: MDPI stays neutral with regard to jurisdictional claims in published maps and institutional affiliations.

Copyright: (c) 2021 by the authors. Licensee MDPI, Basel, Switzerland. This article is an open access article distributed under the terms and conditions of the Creative Commons Attribution (CC BY) license (https:// creativecommons.org/licenses/by/ $4.0 /)$.

\begin{abstract}
The emissions generated by the space and water heating of UK homes need to be reduced to meet the goal of becoming carbon neutral by 2050. The combination of solar (S) collectors with latent heat thermal energy storage (LHTES) technologies with phase change materials (PCM) can potentially help to achieve this goal. However, there is limited understanding of the environmental sustainability of LHTES technologies from a full life cycle perspective. This study assesses for the first time 18 environmental impacts of a full S-LHTES-PCM system from a cradle to grave perspective and compares the results with the most common sources of heat in UK homes. The results show that the system's main environmental hotspots are the solar collector, the PCM, the PCM tank, and the heat exchanger. The main cause of most of the impacts is the extensive consumption of electricity and heat during the production of raw materials for these components. The comparison with other sources of household heat (biomass, heat pump, and natural gas) indicates that the S-LHTES-PCM system generates the highest environmental impact in 11 of 18 categories. However, a sensitivity analysis based on the lifetime of the S-LHTES-PCM systems shows that, when the lifetime increases to 40 years, almost all the impacts are significantly reduced. In fact, a 40-year S-LHTES-PCM system has a lower global warming potential than natural gas.
\end{abstract}

Keywords: thermal energy storage (TES); latent heat thermal energy storage (LHTES); circular economy; environmental sustainability; life cycle assessment (LCA); climate change

\section{Introduction}

The main goal of the Paris Agreement is to limit global warming to well below $2{ }^{\circ} \mathrm{C}$, preferably to $1.5^{\circ} \mathrm{C}$, compared to pre-industrial levels [1]. The UK is one of the 192 signatories and has already taken some steps towards low carbon growth. For example, the UK electricity generation sector produced $48.5 \%$ of the electricity with low carbon technologies in 2019 [2]. Nevertheless, to meet the goals of the Paris Agreement and become carbon neutral by 2050 [3], the emissions generated by the heating of homes and industry need to be reduced, as they currently account for almost a third of all the total current UK emissions [4]. As stated by the Committee on Climate Change [5], to meet the mentioned net-zero target, the UK has to move entirely to a low-carbon heating system by 
2050, which implies that by 2035 , the installation of new gas boilers needs to be phased out and replaced by low-carbon heating systems.

Thermal energy storage (TES) is a form of energy storage that can store heat or cold to be used later [6]. This energy storage mechanism is a possible solution to reduce environmental impacts by balancing the energy demand and supply on a daily, monthly, or seasonal basis [6]. Likewise, the implementation of TES can facilitate the integration of heat pumps or solar collectors into the energy network because the combination of both can reduce the cost of distributed heating for consumers by taking advantage of time-of-use electricity rates. The idea behind this strategy is to store heat in off-peak price periods and release that heat in on-peak price periods [7]. Currently, there are three TES technologies with different readiness levels: sensible heat storage (SHS), thermochemical heat storage (THS), and latent heat thermal energy storage (LHTES). In the case of SHS, heat is stored or released due to a temperature change of the stored material (normally water). The main benefits of SHS are relatively low prices and the use of non-harmful materials. However, the low energy density of this technology causes the use of large quantities of stored material. For example, the energy stored density of an SHS system using water is 84 $\mathrm{MJ} / \mathrm{m}^{3}$, whereas for an LHTES system using salt hydrates is $300 \mathrm{MJ} / \mathrm{m}^{3}$ [6]. Hence, the deployment of these systems requires vast areas, making it viable only at industrial scale. On the other hand, THS technologies are promising due to their highest energy densities and lower heat losses. These technologies charge heat during an endothermic reaction and discharge it during an exothermic reaction. Nevertheless, these technologies are still not commercially available [8]. Lastly, LHTES stores energy through the phase change of the storage medium. Its energy density is significantly higher than SHS, meaning the system can be more compact, and it absorbs and releases heat at a constant temperature, which makes the process more efficient and with less thermal loss. The storage media for LHTES are phase change materials (PCM) with high latent heat of fusion, which allows them to store large amounts of heat when the material changes phase [9]. Nonetheless, these materials have low thermal conductivity, making the charging and discharging of the TES system slow, unless high conducting material such as graphite powder is added. Moreover, incongruently melting PCMs (materials that do not melt uniformly), like many salt hydrates, tend to suffer from phase separation phenomenon, which reduces the heat storage capacity over repeated heating and cooling storage cycles. However, this problem can be solved by selectively adding thickening agents, which limit the distance that the phases can separate by increasing the viscosity of the PCM mixture [10]. Finally, "supercooling" prevents the heat of fusion from being released during the discharge process when the melting point of the PCM is reached, and it is usually avoided by using various nucleating agents. However, stable supercooling is sought in long-term LHTES to minimize the heat losses to the environment, as described in Dannemand et al. [11].

LHTES systems with PCM are technologically ready to be implemented commercially [12]. However, the environmental sustainability of LHTES systems with PCM has been scarcely analysed in the scientific literature. Jungbluth [13] performed a life cycle assessment (LCA) on only the production stage of a phase change material (sodium acetate) for energy storage. The study is based in Germany and is focused only on evaluating the global warming potential and cumulative energy demand of sodium acetate. The results showed that the total greenhouse gas emissions for PCM production are about $5 \mathrm{~kg} \mathrm{CO}_{2}$ eq. per $\mathrm{kg}$ of sodium acetate produced. Moreover, this study concluded that the incineration of the PCM and electricity consumption during its production are the main environmental hot spots in terms of global warming potential. Noël et al. [14] performed another LCA focused on the embodied energy and $\mathrm{CO}_{2}$ emissions of an organic biosourced PCM (Dodecanoic acid) for energy storage. Results showed that this PCM is feasible in energy terms, since less than two years are needed to pay back the embodied energy. Additionally, this PCM could reduce up to $16 \mathrm{tCO}_{2}$ eq. the greenhouse emissions in a typical house in the USA (over a 10 -year period). Hence, to date, there are no studies that consider the whole life cycle of 
the LHTES systems, a wide range of environmental impacts (and potential trade-offs) and the comparison with other sources of heat at the house level.

Regarding the assessment of the combination of solar energy and TES systems, Lamnatou et al. [15] reviewed existing literature on the environmental impact of different storage systems used for building-integrated photovoltaic (BIPV) and building-integrated photovoltaic/thermal (BIPVT) installations. The storage systems analyzed were batteries, PCM, and water tanks in different countries such as Canada and the USA. This review concluded that the environmental impact of a configuration depends on the PCM used and the climate conditions, and found that PCM components present a high environmental impact in human toxicity and ecotoxicity categories. Nevertheless, it is worth noting that the studies focused on paraffins and salt-based PCMs used as envelopes of a building and not as the storage medium of an LHTES system, and considered only a limited amount of environmental impact categories. Moreover, none of the reviewed studies analyzed the environmental impacts of the whole heating system of the building (PV panels, heat exchangers, piping, storage system, pumps, valves, etc.).

Therefore, this study investigates, for the first time, 18 environmental impacts and main hotspots of a solar-powered LHTES (S-LHTES) system using sodium acetate trihydrate (SAT) as PCM for short- and long-term heat storage integrated in a UK household combined heating system (hot water and space heating). This approach gives a much more holistic perspective of the environmental sustainability of the S-LHTES-PCM system, observing potential trade-offs between different impacts and proposing improvements based on the hotspots. SAT was selected due to the suitable melting temperature, the high latent heat of fusion and the ability to supercool consistently down to temperatures well below the ambient temperature. The environmental performance of this system is compared, also for the first time, with the most common heat systems in UK households (natural gas, biomass, and heat pumps). Firstly, the methodology used to perform the LCA and calculate the impact categories is described in Section 2. Secondly, the results for the S-LHTES-PCM system, a sensitivity analysis related to the extension of the lifetime of the system and the comparison with other common sources of heat are explained and discussed in Section 3. Finally, the main conclusions are summarised in Section 4.

\section{Methods}

The life cycle environmental impacts of the combined solar heating system using SAT heat storage have been calculated using the ISO 14040/44 guidelines [16,17]. In compliance with these standards, the study followed the four LCA phases: (i) goal and scope definition; (ii) inventory analysis; (iii) impact assessment, and (iv) interpretation of the results. These stages are described in the next sections.

\subsection{Goal and Scope}

The goal of this study is to assess the environmental impacts of an S-LHTES-PCM system and compare it with other common sources of domestic heat in the UK using an attributional LCA. The LHTES system will store heat produced by solar collectors using SAT as the PCM and its purpose is to supply heating and domestic hot water to a household in the UK.

To accomplish the stated aim, the functional unit (FU) selected for the study was $1 \mathrm{kWh}$ of heat produced by the novel S-LHTES-PCM system. This unit was selected because the main purpose of the system is to provide heat. Moreover, this FU allows to compare the results obtained with other energy storage technologies or sources of heat, irrespective of the size of the systems. For example, Oró et al. [18] performed a comparative LCA of three different thermal energy storage systems for solar power plants, and the same FU was selected.

The system boundaries of the study illustrated in Figure 1 are from cradle to grave, including the following activities and stages:

- Production of materials: 
- Phase change material mixture: SAT (which is the PCM) and Carboxymethyl Cellulose (CMC, thickening agent);

- Evacuated tube solar collector, which includes glass, copper, propylene glycol, and stone wool;

- Water and PCM storage tanks, made of foam and steel;

- Stainless steel (used in the hot water tank, the PCM storage tanks, heat exchanger, and pumps)

- Other materials: rubber (used in solar collectors), butyl acrylate (used in expansion vessels) and cast iron, aluminium, and polyvinylchloride (all used in pumps).

- Manufacturing of:

- Hot water tanks, PCM tanks, solar collectors, PCM, piping, pumps, expansion vessels, heat exchangers, valves, stratifier, and the crystallization activation device. On the other hand, the hydronic circuits with the radiators and taps/showers were not included because they are not part of the S-LHTESPCM system per se and are components that a typical UK household already has.

- Use:

Electricity consumption of the pumps to circulate the water.

- $\quad$ End of life:

- Disposal of components after they have reached their life expectancy.

- Distribution:

- Transport of all the components from production to the household in the UK and to the treatment plant at the end of life.

\subsection{Inventory Data}

The life expectancy of the whole system (20 years) and corresponding components was obtained from existing literature and warranty documents produced by manufacturers (Table 1). A sensitivity analysis has been performed to assess the effect on the environmental impacts of changes in the life expectancy of the S-LHTES-PCM system (see Section 2.3). The S-LHTES-PCM system reaches a solar fraction of heat supply equal to 56\% [19]. Since the total annual energy consumption of the house is $3723 \mathrm{kWh}[11,19]$, this means $2085 \mathrm{kWh}$ are provided by the S-LHTES-PCM system (41,700 kWh in 20 years). It is worth noting that the annual energy consumption of $3723 \mathrm{kWh}$ is typical of a low-energy single-family house built according to the passive house standard located in a Danish climate (similar weather conditions as in the UK). The total energy consumption is the sum of two contributions: the space heating demand (2031 kWh) and the domestic hot water demand (1692 kWh) [11,19]. To calculate the domestic hot water demand, a daily water consumption equal to $99 \mathrm{~L} /$ day was considered (33 L draw off at 7.00, 12:00, and 18:00), assuming a supply temperature of $50{ }^{\circ} \mathrm{C}$ and a cold-water temperature of $10^{\circ} \mathrm{C}$. The space heating demand was calculated on an hourly basis using a building energy simulation tool and the weather data of the Danish climate (similar weather conditions as in the UK). The space heating system was a low-temperature system (floor heating).

The inventory data for the S-LHTES-PCM system is detailed in Table 2. Scientific articles have been used as the main source of primary production data, including the amount and type of raw materials and the electricity and heat consumption during production $[11,19,20]$. Where there was no information available in the literature, the manufacturer's product catalogues were consulted [21-23]. The database Ecoinvent v3.7 [24] was used as the primary source for background data, while the NREL USLCI database [25] was used to fill data gaps. The following sections describe the inventory data in more detail. 


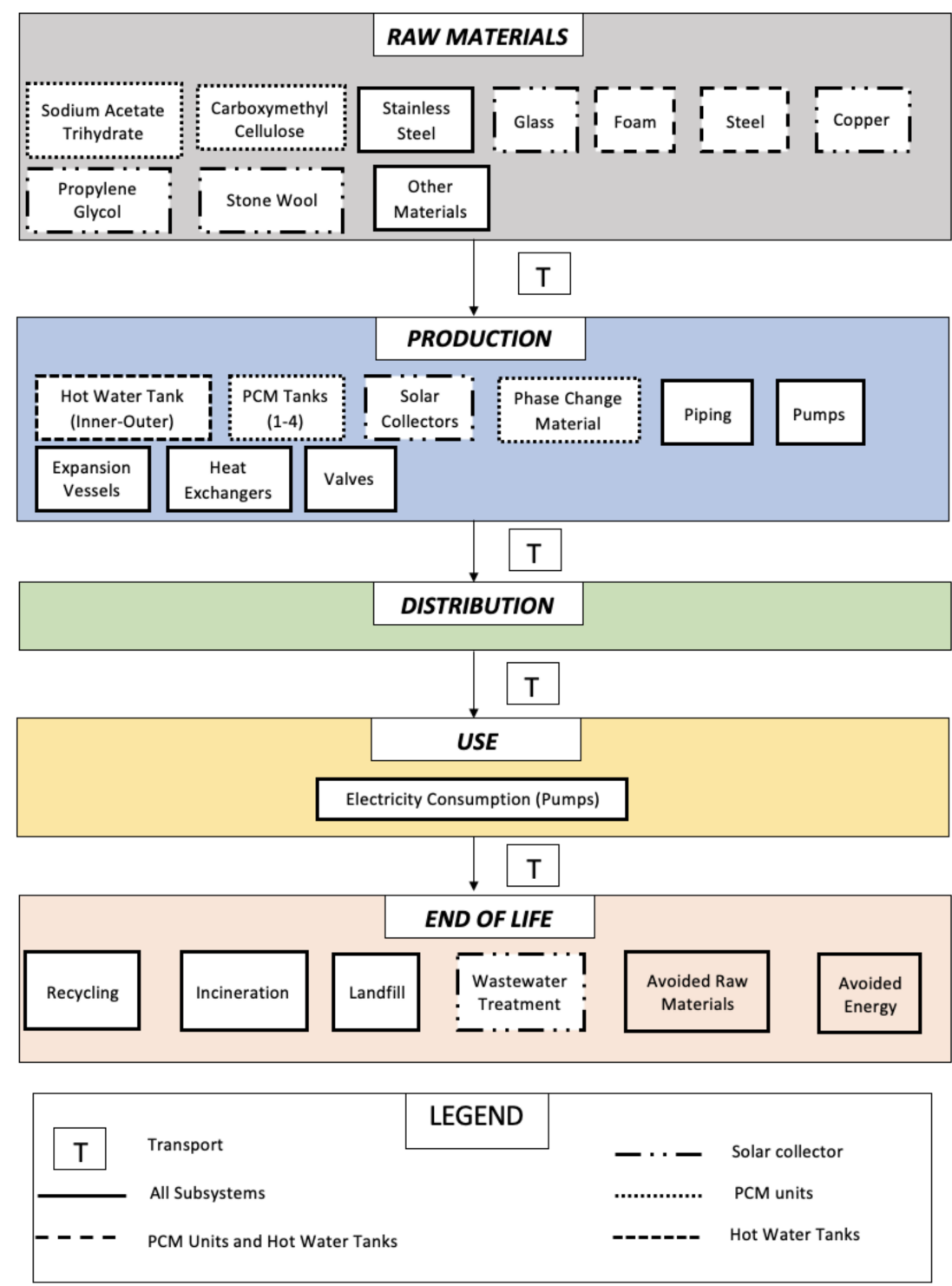

Figure 1. System boundaries for a latent heat thermal energy storage system with phase change materials (PCM), including solar collectors and hot water tanks. (Other materials include rubber (solar collector) butyl acrylate (expansion vessel), acrylonitrile butadiene styrene (stratifier and activation device) and cast iron, aluminium, and polyvinylchloride (pumps)).

Table 1. Lifetime expectancy of all the components used in a solar energy and latent heat thermal energy storage system with phase change material.

\begin{tabular}{ccc}
\hline Component & Lifetime & Reference \\
\hline Phase change material & 10 years & {$[26]$} \\
Heat exchanger & 30 years & {$[27]$} \\
Inner tank & 25 years & {$[28]$} \\
Solar collector & 20 years & {$[21]$} \\
Heat transfer fluid & 3 years & {$[23]$} \\
Water pump & 5 years & {$[24]$} \\
Expansion vessels & 15 years & {$[29]$} \\
Piping & Copper 40 years & {$[30]$} \\
Valves & Steel 40 years & {$[31]$} \\
\hline
\end{tabular}


Table 2. Inventory data for a solar energy and latent heat thermal energy storage (S-LHTES) system with phase change material (PCM). All values are expressed per $1 \mathrm{kWh}$ of heat produced by the system.

\begin{tabular}{|c|c|c|}
\hline Life Cycle Stage & S-LHTES-PCM & Reference \\
\hline \multicolumn{3}{|l|}{ Raw materials } \\
\hline Sodium acetate trihydrate $(\mathrm{PCM})(\mathrm{g})$ & 41.8 & \\
\hline Carboxymethyl cellulose (PCM) (g) & 0.4 & {$[10,11,32]$} \\
\hline $\begin{array}{l}\text { Stainless steel (hot water tank, PCM tanks, heat exchanger, solar } \\
\text { collector, and pumps) (g) }\end{array}$ & 12.7 & {$[21,22,24,28,32,33]$} \\
\hline Glass tube (solar collector) $(\mathrm{g})$ & 7.6 & {$[21,24]$} \\
\hline Foam (hot water tank, PCM-tanks) (g) & 5.8 & [20] \\
\hline $\begin{array}{l}\text { Carbon steel (hot water tank, piping, heat exchanger, expansion } \\
\text { vessel, and valves) (g) }\end{array}$ & 19.6 & {$[22,24,28,32]$} \\
\hline Copper (solar collector, piping, and pumps) (g) & 1.5 & {$[21,24]$} \\
\hline Propylene glycol (solar collector) (g) & 2 & [23] \\
\hline Stone wool (solar collector) (g) & 1.1 & {$[21,24]$} \\
\hline Other materials (solar collector, expansion vessel, and pumps) (g) ${ }^{a}$ & 0.9 & {$[21,24]$} \\
\hline \multicolumn{3}{|l|}{ Production } \\
\hline Electricity (all elements) (kJ) & 99.7 & \\
\hline Heat (all elements) $(\mathrm{kJ})$ & 29 & {$[13,24,34]$} \\
\hline \multicolumn{3}{|l|}{ Transport } \\
\hline Freight lorry (all elements) (kg·km) & 2.1 & \\
\hline Freight train (all elements) (kg.km) & 0.02 & {$[24]$} \\
\hline \multicolumn{3}{|l|}{ Use } \\
\hline Electricity Consumption (kJ) & 12.9 & [32] \\
\hline \multicolumn{3}{|l|}{ End of Life } \\
\hline Recycling: Plastics (g) & 1.8 & [35] \\
\hline Recycling: Metals (g) & 27 & {$[36,37]$} \\
\hline Incineration with energy recovery: Plastics (g) & 3.4 & [35] \\
\hline Incineration with energy recovery: PCM (g) & 42.2 & [13] \\
\hline Incineration with energy recovery: Stone wool (g) & 0.7 & [38] \\
\hline Landfilling: Plastics (g) & 1.3 & [35] \\
\hline Landfilling: Glass (g) & 7.6 & [39] \\
\hline Landfilling: Metals (g) & 5.1 & {$[36,37]$} \\
\hline Landfilling: Stone wool (g) & 0.4 & [38] \\
\hline Wastewater treatment $(\mathrm{l})$ & 0.005 & [24] \\
\hline
\end{tabular}

a Other materials: Rubber (solar collector) $0.4 \mathrm{~g}$; butyl acrylate (expansion vessel) $0.2 \mathrm{~g}$; cast iron (pumps) $0.4 \mathrm{~g}$, aluminium (pumps) $0.006 \mathrm{~g}$; and polyvinchloride (pumps) $0.01 \mathrm{~g}$ and acrylonitrile butadiene styrene (activation device and stratifier) $0.04 \mathrm{~g}$.

\subsubsection{Raw Materials}

The whole S-LHTES-PCM system is divided into three subsections as illustrated in Figure 2: (i) the solar collector unit, (ii) the PCM storage unit, and (iii) the hot water tank unit.

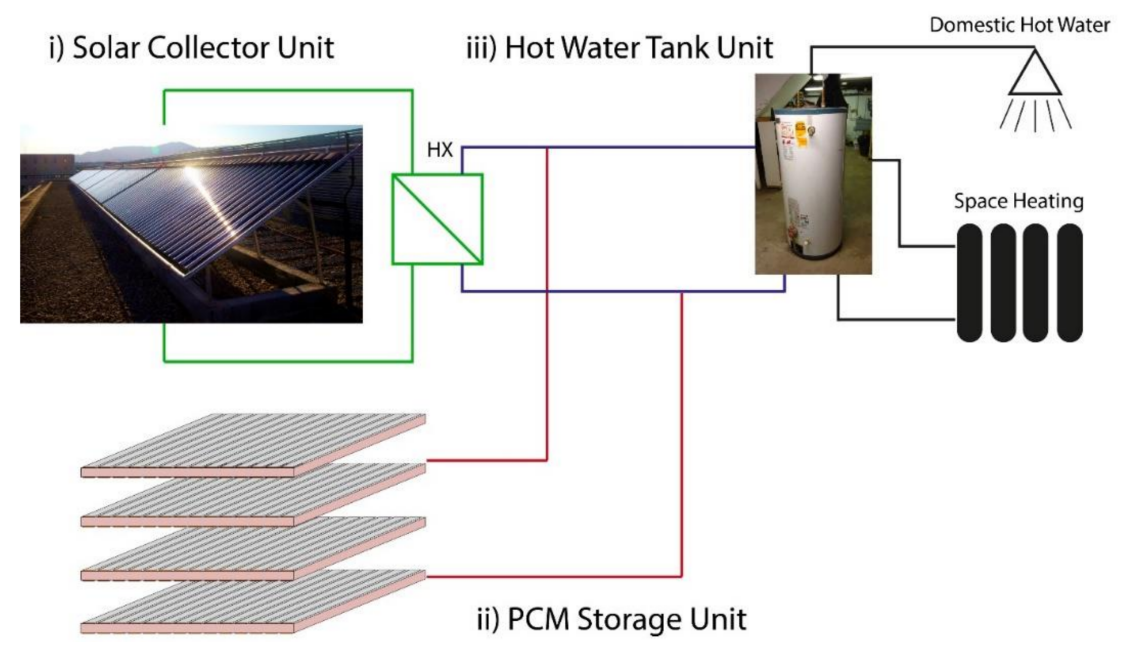

Figure 2. Diagram of a solar energy and latent heat thermal energy storage (S-LHTES) system with phase change material (PCM). Adapted from Englmair et al. [19]. 
The solar collector subsystem includes the solar collectors, a plate heat exchanger, the heat transfer fluid, and a copper piping section. Seven evacuated tubular collectors with an aperture area of $3.2 \mathrm{~m}^{2}$ each have been considered. Specifically, the Thermomax HP 450 tubular collectors from Kingspan Solar were selected due to their low heat loss coefficient [21]. This low coefficient enables higher temperatures of the heat transfer fluid and, in turn, the achievement of the conditions required for stable supercooling of SAT [11]. According to the data reported by Kingspan Solar [21], the absorber is made of copper with a TiNO coating reaching 95\% absorbance. Each collector is composed of thirty low-iron glass tubes, which maintain a vacuum condition [21]. Additionally, stainless steel and ethylene propylene diene monomer (EPDM) rubber are needed for the mounting frames and clips. A layer of stone wool is also needed to increase insulation. The Ecoinvent dataset [24] for a home solar collector system with evacuated tube collectors was adapted according to the design characteristics mentioned above. The heat transfer fluid considered is TYFOCOR-LS liquid, which is an aqueous solution of propylene glycol [23]. As stated by Kingspan Solar [21], each solar collector needs $1.7 \mathrm{~L}$ of fluid, so taking into account the life expectancy stated in Table 1, and the density of propylene glycol, $116.9 \mathrm{~kg}$ of propylene glycol have been considered ( $2.0 \mathrm{~g} / \mathrm{FU})$. The plate heat exchanger is composed of $2.5 \mathrm{~kg}$ of stainless steel $(0.06 \mathrm{~g} / \mathrm{FU})$ and $31 \mathrm{~kg}$ of carbon steel $(0.74 \mathrm{~g} / \mathrm{FU})$ [22].

The raw materials for the PCM unit subsystem were obtained from LHTES system studies $[10,11,32]$. According to these studies, four separate modules of $150 \mathrm{~L}$ each, composed the PCM storage unit. Considering the life expectancies in Table 1, 11,742.4 kg of SAT $(41.8 \mathrm{~g} / \mathrm{FU})$ and $17.8 \mathrm{~kg}(0.4 \mathrm{~g} / \mathrm{FU})$ of carboxymethyl cellulose are needed as PCM and thickening agent, respectively. To store this quantity of PCM mixture, four stainless steel tanks are needed to avoid corrosion [33]. Each tank features an insulation layer of $10 \mathrm{~cm}$ of rigid foam to minimize thermal losses, which is the most common type of advanced heating insulation material used in industry [20].

A parallel channel heat exchanger made of steel is used to achieve a high heat exchange capacity rate in the PCM unit, which is an important factor for the system performance. The channels have an internal height of $4 \mathrm{~mm}$ and a width of $130 \mathrm{~mm}$ separated by $20 \mathrm{~mm}$ spacers, as reported by Englmair et al. [32]. In total, there are 16 parallel channels at the bottom of the PCM chamber and 14 on the top. The weight of the heat exchanger $(13.8 \mathrm{~g} / \mathrm{FU})$ was obtained by estimating the difference between the total weight of each empty unit and the weight of the PCM container.

The dimensions for the hot water tank unit were gathered from Englmair et al. [10], where a "tank in tank" technology provides both domestic hot water and space heating for the house. The outer tank and inner tanks have dimensions of $0.8 \mathrm{~m} \times 1.6 \mathrm{~m} \times 0.002 \mathrm{~m}$ and $0.45 \mathrm{~m}$ $\times 1.1 \mathrm{~m} \times 0.002 \mathrm{~m}$, respectively. To obtain the raw materials used in the "tank in tank", data provided by a hot water tank manufacturer called ACV was used [28]. According to $\mathrm{ACV}$, the outer tank is made of steel with a $0.05 \mathrm{~m}$ insulation layer of rigid foam, while the inner tank is made of stainless steel. Additionally, the inner tank has a citric acid coating to improve the corrosion resistance properties of the material. Englmair et al. [32] also state that the hot water tank needs a polymeric inlet stratifier (for properly admitting the hot water). It has been assumed that the stratifier is made of acrylonitrile butadiene styrene (ABS) and that it is a cylinder with an inner diameter of $16 \mathrm{~mm}$, an outer diameter of $20 \mathrm{~mm}$ and a height of $1.6 \mathrm{~m}$.

The S-LH-PCM system also needs extra components such as piping sections, pumps, expansion vessels, and valves. A total number of 11 valves, five $50 \mathrm{~L}$ expansion vessels and three $50 \mathrm{~W}$ pumps are needed [32]. For these components, the Ecoinvent dataset [24] was used. Regarding the piping used for this heating system, the weight per unit of length was obtained from the inner and outer diameters and the type of material reported in Aste and Groppi [40] (see Table S1 in Supporting Materials). 


\subsubsection{Production}

All the components were assumed to be manufactured in the UK unless stated differently. The Ecoinvent 3.7 dataset [24] was used to obtain the amount of electricity and heat consumption during the production of most of the components. However, for the PCM, the data was obtained from a chemical company (SGL Carbon, 2021) and the PCM was assumed to be produced in Germany [13]. For all the storage tanks, the consumption of energy during the production was obtained from an LCA of household water tanks [34].

\subsubsection{Use}

The electricity consumption of the pumps was estimated from the power rating of the devices. There were three pumps with a power consumption of $50 \mathrm{~W}$ each and operating for $3000 \mathrm{~h} / \mathrm{yr}$. Therefore, the total electricity consumption of the system is $150 \mathrm{kWh} / \mathrm{yr}$ and $12.9 \mathrm{~kJ} / \mathrm{FU}$ (Table 2).

\subsubsection{Transport}

The transportation distances of the different raw materials and components from the market processes of the Ecoinvent 3.7 database [24] have been considered due to the lack of specific data from the suppliers. Regarding the transportation devices, the hot water tanks and PCM tanks were assumed to be transported from the production site to the household by a 16-32 $t$ Euro 6 lorry. For the PCM, 16-32 $t$ Euro 6 lorries and freight trains were considered. Lastly, for the waste treatment, a distance of $50 \mathrm{~km}$ in a 16-32 t Euro 6 lorry was assumed for all the materials used.

\subsubsection{End of Life}

Table 3 illustrates the type of treatment, values, and literature references considered for each raw material. Average UK values for recycling, incineration, and landfilling were used for each raw material. The wastewater treatment associated with the end of life of the heat transfer fluid (propylene glycol) has also been considered. The "net scrap" approach was applied for recycling [41], meaning that only the percentage of recycled material that exceeds the recycled content in the original raw materials has been credited to the system. The environmental impact associated with the recycling process has also been included and, in the case of incineration, the amount of energy produced during the process (heat and electricity) has been attributed to the system. The Ecoinvent 3.7 database [24] has been considered for all waste and wastewater treatment methods.

Table 3. End of life treatment for different raw materials in the UK.

\begin{tabular}{ccccc}
\hline Material & Recycle & Landfill & Incineration & Reference \\
\hline Plastics & $28 \%$ & $20 \%$ & $52 \%$ & {$[35]$} \\
Steel and cast iron & $85 \%$ & $15 \%$ & & {$[36]$} \\
Stone wool & & $39 \%$ & $61 \%$ & {$[38]$} \\
Tempered glass & & & $100 \%$ & {$[39]$} \\
Copper & $65 \%$ & $35 \%$ & & {$[37]$} \\
Phase change material & & & $100 \%$ & {$[13]$} \\
\hline
\end{tabular}

\subsection{Sensitivity Analysis}

A sensitivity analysis was performed to assess the effect on expanding the life expectancy of the S-LHTES-PCM system. The lifetime of each part of the system is highly uncertain as it depends on variable aspects such as the level of maintenance. S-LHTES-PCM systems are a new and under development technology, and there is the potential to increase the life expectancy of the different parts of the system with appropriate maintenance, in line with the circular economy strategy of slowing [42-44]. For this reason, it has been estimated that the heat exchanger and inner tank can increase their useful life up to 40 years (from the initial 20 years; see Table 1), while the solar collector, expansion vessels, and PCM useful life can be increased to 25, 20, and 15 years, respectively (from the initial 
20,15 , and 10 years; see Table 1). For pipes, valves, and water pumps, the useful life was not changed. Considering these premises, the sensitivity analysis considers different levels of lifetime extension $(25,30,35$, and 40 years of operation) and compares them with the current situation (20 years).

\subsection{Comparison with Current Sources of Heat in the UK}

Current heat generation scenarios for households in the UK were analyzed and compared with the S-LHTES-PCM system. Data was collected from Ecoinvent 3.7 [24] and adapted to the UK conditions when possible (e.g., UK electricity grid and UK natural gas). The following heat generation scenarios were evaluated: (i) biomass, (ii) heat pump, (iii) natural gas, (iv) S-LHTES-PCM system, and (v) S-LHTES-PCM system with 40 years of lifetime (see Section 2.3). Natural gas was selected because it is the main source of heat in UK households ( $76 \%$ of the total) and biomass and heat pumps because they are considered low-carbon sources [45]. The biomass system includes the production of natural wood from the forest, infrastructure, air emissions, electricity required for operation, and ash disposal. The Ecoinvent database [24] considers wood-fired furnaces for domestic use with nominal capacities of less than $15 \mathrm{~kW}$. For the heat pump, the Ecoinvent database was adapted to European conditions. The system has a heat capacity of $10 \mathrm{~kW}$ and a lifetime of 20 years. The heat pump system delivered approximately 20,000 kWh in 2000 operating hours and Ecoinvent 3.7 [24] includes emissions of the refrigerant R134a during operation. For the natural gas system, the Ecoinvent database includes a mix of central and small-scale gas boilers, natural gas production, the energy requirements (electricity, heat, and burnt natural gas), and the emissions of the high-pressure distribution network from the UK.

\subsection{Impact Assessment}

SimaPro 9.1 software has been used to model the system and the impact categories have been calculated according to the "Recipe 2016 midpoint $(\mathrm{H})$ " methodology [46]. The following impact categories have been considered: global warming potential (GWP), stratospheric ozone depletion potential (ODP), ionizing radiation potential (IRP), ozone formation potential, human health (OFPh), fine particulate matter formation potential (PMP), ozone formation potential, terrestrial ecosystems (OFPt), terrestrial acidification potential (TAP), freshwater eutrophication potential (FEP), marine eutrophication potential (MEP), terrestrial ecotoxicity potential (TEP), freshwater ecotoxicity potential (FETP), human carcinogenic toxicity potential (HTPc), human non-carcinogenic toxicity potential (HTPnc), agricultural land occupation potential (ALOP), mineral depletion potential (MDP), fossil depletion potential (FDP), water consumption potential (WDP), and cumulative energy demand (CED).

\section{Results}

\subsection{Life Cycle Assessment}

As shown in Figure 3, the system's main environmental hotspots are the solar collector in nine of the 18 impact categories (contributions between $35 \%$ in OFPh and $73 \%$ in FETP), the PCM in five categories (between 26\% in GWP and 65\% in WDP), the PCM tank in three categories (between 35\% in MEP and 49\% in ODP), and the heat exchanger is the main contributor to HTPc ( $30 \%$ of the total). Altogether, these parts contribute over $83 \%$ in all the 18 impact categories evaluated.

For solar collectors the evacuated tube collector is the leading environmental hotspot, representing between 67\% (water consumption, WDP) and 90\% (land use, ALOP) of solar collector-related impacts in all categories evaluated. These impacts are mainly associated with the raw materials (particularly copper and borosilicate glass) in the evacuated tube collector and the production processes. For example, over $90 \%$ of the impacts of the evacuated tube collector in the TEP, FEP, and HTPnc categories are associated with its copper content. The borosilicate glass is the primary environmental hotspot of the evaluated tube collector in the GWP, IRP, OFPh, ALOP, and FDP impact categories, with contributions over 
$35 \%$. In GWP, the impact is mainly associated with the electricity and heat consumption in the borosilicate glass production plant. Electricity consumption is also responsible for $82 \%$ of the solar collector-related IRP impact. In the OFPh category, $\mathrm{NO}_{x}$ emissions generated in the glass tube production plant are responsible for $54 \%$ of the impact of the evacuated tube collector. Heat and electricity used in the production contribute, respectively, $40 \%$ and $35 \%$ of the FDP impact of the evacuated tube collector.

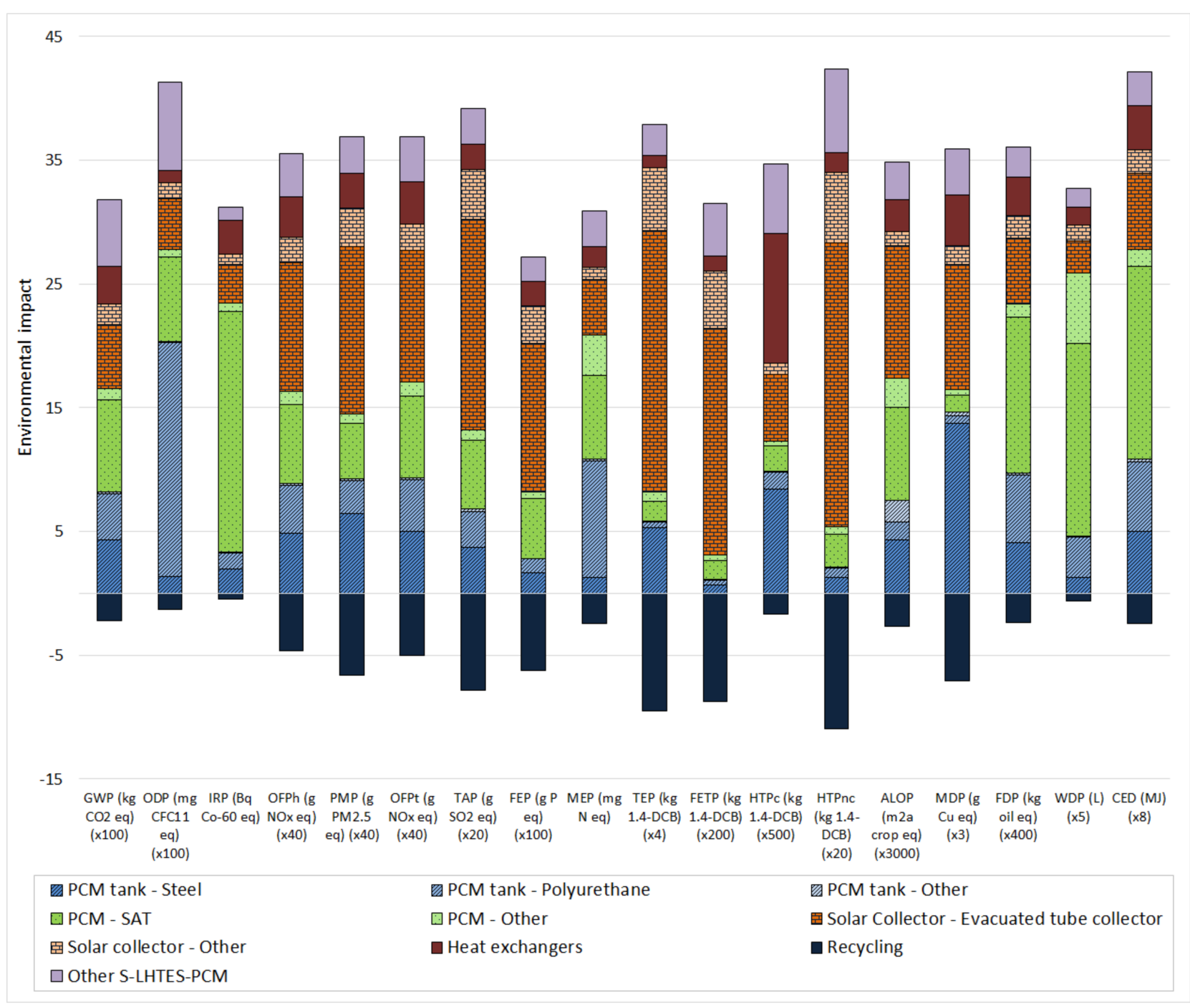

Figure 3. Environmental contribution analysis of a solar domestic system with latent heat thermal energy storage technology with phase change material (S-LHTES-PCM). (All impacts are expressed per kWh of heat produced. GWP: global warming potential; ODP: ozone depletion potential; IRP: ionising radiation potential; OFPh: ozone formation potential, human health; PMP: fine particulate matter formation potential; OFPt: ozone formation potential, terrestrial ecosystems; TAP: terrestrial acidification potential; FEP: freshwater eutrophication potential; MEP: marine eutrophication potential; TEP: terrestrial ecotoxicity potential; FETP: freshwater ecotoxicity potential; HTPc: human carcinogenic toxicity potential; HTPnc: human non-carcinogenic toxicity potential; ALOP: agricultural land occupation potential; MDP: mineral depletion potential; FDP: fossil depletion potential; WDP: water depletion potential; CED: Cumulative energy demand; SAT: Sodium acetate trihydrate).

With regards to the PCM subsystem, SAT contributes to the highest environmental burden, accounting for $68 \%$ (MEP and TEP) and $96 \%$ (IRP) of the impact of the PCM. As illustrated in Figure 3, SAT is the leading environmental contributor in the whole S-LHTESPCM system in the GWP (23\% of the total), IRP (62\%), FDP (35\%), WDP ( $48 \%)$, and CED $(37 \%)$ categories. The main environmental hotspots in the SAT life cycle are associated with 
the electricity used in the production of the components (sodium hydroxide and acetic acid), and to a lesser extent, in the production process of sodium acetate trihydrate. As for the PCM tank, steel and polyurethane (foam) represent the major environmental impacts. These parts of the PCM tank represent $68 \%$ (ALOP) and 100\% (ODP) of the impact of the PCM system. Polyurethane is one of the main environmental hotspots of the PCM tank in the categories of ODP (93\% of the contribution of the whole PCM system), MEP ( $87 \%$ ), FDP $(57 \%)$, WDP $(71 \%)$, and CED (52\%). These impacts are mainly due to the use of methylene diphenyl diisocyanate (MDI) in polyurethane production. Nitrate emissions to water in MDI production are responsible for $80 \%$ of the MEP impact of the PCM system. The other categories mentioned above (ODP, FDP, WDP, and CED) are strongly influenced by the use of aniline in the MDI production process. If we focus on the PCM tank, steel is the main environmental hotspot in 13 out of the 18 impact categories analysed. In the GWP category, heat production from hard coal industrial furnaces and electricity production are the steel main environmental hotspots. Emissions of particulate matter $<2.5 \mu \mathrm{m}$ in the ferrochromium production process is the main environmental hotspot in the PMP category, accounting for $47 \%$ of the impact of steel on the PMP category. In the TEP category, air emissions of copper in ferronickel production are responsible for $60 \%$ of the steel impact. Air emissions of chromium VI associated with ferrochromium production are responsible for $48 \%$ of the HTPc impact, while nickel ore consumption in ferronickel production is responsible for $85 \%$ of the impact in the MDP category.

End-of-life stages generate both environmental benefits and impacts. Steel recycling generates higher environmental benefits in eight impact categories (GWP, OFPh, OFPt, MEP, ALOP, MDP, FDP, and CED), while copper does so in ten (ODP, IRP, PMP, TAP, FEP, TEP, FETP, HTPc, HTPcn, and WDP). Overall, recycling reduces the total environmental impacts of the solar energy and S-LHTES-PCM system by up to $28 \%$ (FETP).

\subsection{Sensitivity Analysis: Lifetime Extension}

A sensitivity analysis was performed based on the lifetime of the S-LHTES-PCM system (see Section 2.3). As shown in Figure 4, the increase of life expectancy of the SLHTES-PCM system to 25 years significantly reduces the environmental impacts in all the evaluated categories. However, when the lifetime increases to 30 years, the environmental impacts of five categories (FETP, TEP, HTPnc, FEP, and TAP) increase over the impacts of the original system (20 years lifetime). This is because the S-LHTES-PCM system requires the replacement of the solar collector, which has reached its lifetime at 25 years. The solar collector is the leading environmental hotspot of the S-LHTES-PCM system in the five categories mentioned above. Because of this, and given that the system will have a lifetime of 30 years, the new solar collector will only be used for five years, and, therefore, not being able to amortize its environmental burden over its potential lifetime, which increases the impacts of the system.

As illustrated in Figure 4, when the lifetime increases from 30 to 40 years, most of the impacts decrease because the environmental burden of the leading environmental hotspots of the system (PCM and solar collector) are distributed throughout their lifetime. FETP is the only impact category that did not decrease, but had a negligible increase $(0.6 \%)$. The TEP and HTPnc impact categories showed minor decreases when the lifetime increased to 40 years ( $3 \%$ and $4 \%$, respectively). These small variations can be a result of the inherent uncertainty associated with the data. However, these minor variations can be justified because the solar collector is the primary environmental hotspot in these categories (FETP, TEP, and HTPnc). The solar collector initially has a lifetime of 20 years and, although it increases its lifetime to 25 years, two solar collectors are used when the useful life of the SLHTES-PCM system increases to 40 years, which does not affect these categories. However, these categories are affected to a lesser extent by the PCM tank that doubles its lifetime, which generates the environmental benefit observed in the TEP and HTPnc categories. On the other hand, the HTPc, ODP, and GWP categories showed the most significant decreases with $53 \%, 40 \%$, and $36 \%$ reduction, respectively. HTPc presents the highest reduction in all 
the environmental impacts, because its main environmental hotspots are PCM tank $(28 \%)$ and heat exchanger (30\%). Both parts of the S-LHTES-PCM system increase from 20 years to 40 years, which influences the environmental benefits of the HTPc category. For ODP, the main environmental hotspot is the PCM tank (49\%), and, therefore, increasing its lifetime decreases the impact of this category. In GWP, the PCM tank (26\%) and the heat exchanger $(10 \%)$ are two of the main environment hotspots, and increasing their lifetime decreases the global warming impact. This will imply a reduction from $0.29 \mathrm{~kg} \mathrm{CO} 2 \mathrm{eq} . / \mathrm{kWh}$ to $0.19 \mathrm{~kg} \mathrm{CO} 2$ eq. $/ \mathrm{kWh}$ when the lifetime of the S-LHTES-PCM system increases to 40 years. However, it should be noted that increasing the lifetime of the system could potentially increase the cost of repairs and maintenance. Therefore, the economic impact of increasing the lifetime of the system should be analyzed in future studies.

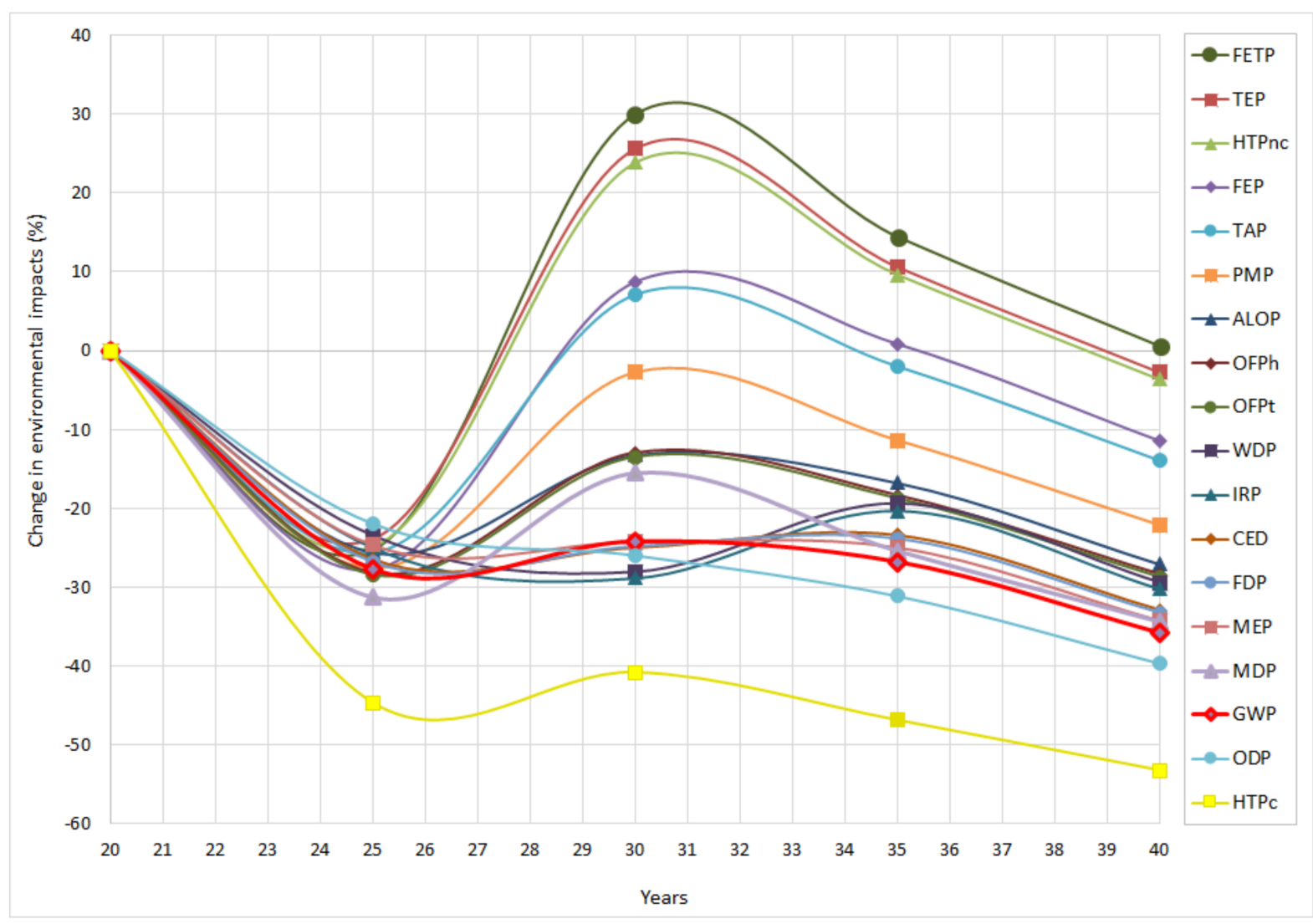

Figure 4. Percentual variation of the environmental impacts for different lifetimes of a solar domestic system with latent heat thermal energy storage technology with phase change material (S-LHTES-PCM). For impact nomenclature, see Figure 3.

\subsection{Comparison with Natural Gas, Biomass and Heat Pumps}

For the scenario analysis, the generation of $1 \mathrm{kWh}$ of heat from biomass, heat pump, natural gas, and two S-LHTES-PCM systems (with regular and extended lifetimes of 20 and 40 years) was considered (see Section 2.3). As illustrated in Figure 5, the S-LHTES-PCM system (20 years) generates the highest environmental impacts in 11 of the 18 categories evaluated (GWP, ODP, TAP, FEP, MEP, TEP, FETP, HTPc, HTPnc, MDP, and WDP). The main cause of these impacts is the emissions from the extraction of raw materials and processes associated with the production of the components of the S-LHTES-PCM system, especially solar collector, PCM, PCM tanks, and heat exchanger (see Section 3.1). In the case of GWP, the S-LHTES-PCM system generates $0.30 \mathrm{~kg} \mathrm{CO} 2$ eq. $/ \mathrm{kWh}$. However, when the life expectancy of the S-LHTES-PCM system is expanded to 40 years, the GWP value is reduced to $0.19 \mathrm{~kg} \mathrm{CO}_{2}$ eq. $/ \mathrm{kWh}$, becoming the third-best option and with similar values to the second (heat pumps with $0.17 \mathrm{~kg} \mathrm{CO}_{2} \mathrm{eq} . / \mathrm{kWh}$ ). Natural gas technology generates 
the second-highest impacts in GWP with $0.27 \mathrm{~kg} \mathrm{CO}$ eq. $/ \mathrm{kWh}$, mainly due to direct emissions from the natural gas combustion process, while biomass technology generates the lowest environmental impacts in the GWP category $\left(0.03 \mathrm{~kg} \mathrm{CO}_{2}\right.$ eq. $\left./ \mathrm{kWh}\right)$. However, biomass presents the highest value in OFPh, OFPt, ALOP, and CED. Although there is a significant amount of biomass in the UK [47], the indigenous biomass resources and energy crops only could service, in the best scenario, up to $44 \%$ of UK energy demand by 2050 [48]. Bioenergy is a key renewable energy technology targeted to provide options for decarbonizing heat, power, and transport energy in the UK. However, there are growing demands for bioenergy for different energy vectors. Therefore, there will likely be growing competition within the bioenergy sector for feedstock [47]. In addition, biomass resources (crop residues, forestry products, waste, and land) also compete with food production, conservation, animal feed, animal bedding, construction material, panel industry, sawmills, pulp and paper industry, among others [47], leading to uncertainty about their future availability in significant amounts for household heating. The heat pump technology has the highest impacts in the IRP category and the second-highest impacts in another ten (TAP, FEP, MEP, TEP, FETP, HTPc, HTPnc, ALOP, MDP, and WDP). The impacts of this technology are mainly associated with the use of energy from the UK electricity system, representing between $60 \%$ to $99 \%$ of all impact categories evaluated.

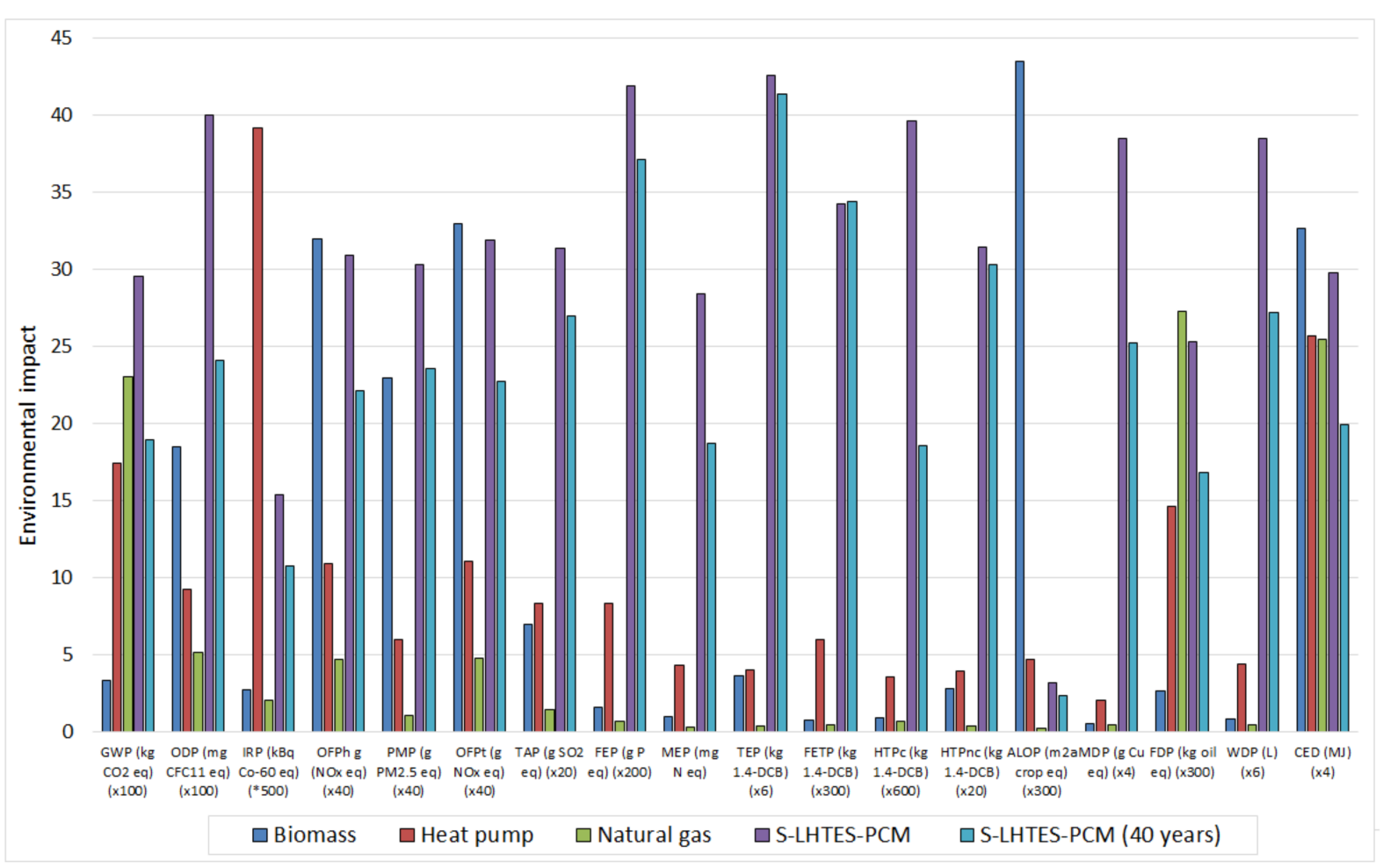

Figure 5. Comparative environmental impact analysis of different types of household energy sources. For acronyms and impact nomenclature, see Figure 3.

Finally, it is essential to highlight that if the lifetime of the S-LHTES-PCM system increases to 40 years, its use in households can minimize most of the environmental impacts. For example, as mentioned above, an S-LHTES-PCM system with a 40 years life expectancy has significantly lower values of GWP compared to natural gas, which is the primary source of energy in households in the UK [45,49]. This is relevant considering that the S-LHTESPCM system is a technology still under development with potential room for improvement. In this sense, improving the efficiency of the S-LHTES-PCM system, applying the circular economy principles regarding maintenance and lifetime expansion, and decarbonizing the UK electricity are options that can improve the environmental performance of the system and minimize all the impacts, including climate change. 


\section{Conclusions}

This study analyses, for the first time, 18 environmental impact categories for an S-LHTES-PCM system. The environmental performance of the system is compared against traditional heat sources in the UK (biomass, heat pumps, and natural gas). Moreover, a sensitivity analysis was performed based on the lifetime of the S-LHTES-PCM system.

Thanks to the implementation of the life cycle assessment methodology, it was possible to identify the main environmental hotspots of the S-LHTES-PCM system: the solar collector, PCM, PCM tank, and heat exchanger. Altogether, these parts contribute over $83 \%$ in all the 18 impact categories evaluated. The environmental impacts are mainly associated with the system's raw materials and the energy consumption in the production processes. For this reason, extending the lifetime of the systems according to circular economy principles improves the system's environmental performance. In this sense, thanks to a sensitivity analysis, it has been demonstrated for the first time that when the S-LHTES-PCM system lifetime is increased to 40 years (from the initial 20 years considered), the environmental performance improves and can be a competitive option from an environmental perspective if compared with other traditional household energy sources, like natural gas, biomass, and heat pumps.

The results of this study will work as a baseline to identify where LHTES systems need to improve before being implemented commercially in the UK. Even more, the general conclusions and hotspots identified can be applied to the implementation of similar systems in other countries. Future research should investigate the social and economic aspects to have a holistic vision that considers the three pillars of sustainable development. The results obtained could be of special interest to stakeholders of the construction and energy sectors and policymakers interested in potential solutions to achieve a more sustainable delivery of space and water heat in households.

Supplementary Materials: The following are available online at https://www.mdpi.com/article/10 .3390 / su132011265/s1, Table S1. Main features of the piping in the phase change material (PCM), collector and water tank circuits. Adapted from Englmair et al. (2020).

Author Contributions: Conceptualization, D.C.B., E.M., G.M., A.S. and A.G.-S.; Data curation, D.C.B. and E.M.; Formal analysis, A.G.-S.; Funding acquisition, A.S., H.A. and A.G.-S.; Investigation, D.C.B., E.M. and A.G.-S.; Methodology, A.G.-S.; Project administration, A.S., H.A. and A.G.-S.; Resources, G.M. and A.G.-S.; Software, D.C.B. and E.M.; Supervision, A.S. and A.G.-S.; Validation, A.G.-S.; Writing—original draft, D.C.B., E.M. and A.G.-S.; Writing—review \& editing, D.C.B., A.S., H.A. and A.G.-S. All authors have read and agreed to the published version of the manuscript.

Funding: The authors would like to acknowledge the financial support received by the EPSRC Supergen Energy Network (EP/S00078X/1) through the Flex Funding of the project 'Whole system analysis impact of thermal energy storage technologies in future UK energy networks'.

Institutional Review Board Statement: Not applicable.

Informed Consent Statement: Not applicable.

Data Availability Statement: The data presented in this study are available on request from the corresponding author.

Acknowledgments: The images in Figure 2 were obtained from Wikimedia Commons. The authors would like to thank Xi Zhang for his contribution to the article with data regarding the main sources of heat in UK households.

Conflicts of Interest: The authors declare no conflict of interest.

\section{Acronyms}

ABS Acrylonitrile butadiene styrene

ALOP Agricultural land occupation potential

BIPV Building integrated photovoltaic

BIPVT Building integrated photovoltaic/thermal 


$\begin{array}{ll}\text { CED } & \text { Cumulative energy demand } \\ \text { CMC } & \text { Carboxymethyl cellulose } \\ \text { EPDM } & \text { Ethylene propylene diene monomer } \\ \text { FDP } & \text { Fossil depletion potential } \\ \text { FEP } & \text { Freshwater eutrophication potential } \\ \text { FETP } & \text { Freshwater ecotoxicity potential } \\ \text { FU } & \text { Functional unit } \\ \text { GWP } & \text { Global warming potential } \\ \text { HTPC } & \text { Human carcinogenic toxicity potential } \\ \text { HTPnc } & \text { Human non-carcinogenic toxicity potential } \\ \text { IRP } & \text { Ionizing radiation potential } \\ \text { LCA } & \text { Life cycle assessment } \\ \text { LHTES } & \text { Latent heat thermal energy storage } \\ \text { MDI } & \text { Methylene diphenyl diisocyanate } \\ \text { MDP } & \text { Mineral depletion potential } \\ \text { MEP } & \text { Marine eutrophication potential } \\ \text { ODP } & \text { Stratospheric ozone depletion potential } \\ \text { OFPh } & \text { Ozone formation potential human health } \\ \text { OFPt } & \text { Ozone formation potential terrestrial ecosystems } \\ \text { PCM } & \text { Phase change material } \\ \text { PMP } & \text { Fine particulate matter formation potential } \\ \text { SAT } & \text { Sodium acetate trihydrate } \\ \text { SHS } & \text { Sensible heat storage } \\ \text { S-LHTES } & \text { Solar power latent heat thermal energy storage } \\ \text { S-LHTES-PCM } & \text { Solar power latent heat thermal energy storage with phase change material } \\ \text { TAP } & \text { Terrestrial acidification potential } \\ \text { TEP } & \text { Terrestrial ecotoxicity potential } \\ \text { TES } & \text { Thermal energy storage } \\ \text { THS } & \text { Thermochemical heat storage } \\ \text { WDP } & \text { Water consumption potential } \\ & \\ & \end{array}$

\section{References}

1. United Nations Climate Change the Paris Agreement. Available online: https://unfccc.int/process-and-meetings/the-parisagreement/the-paris-agreement (accessed on 10 June 2021).

2. National Grid Balancing the Grid. Available online: https://www.nationalgrid.com/britain-hits-historic-clean-energy-milestonezero-carbon-electricity-outstrips-fossil-fuels-2019 (accessed on 28 July 2021).

3. Department for Business Energy \& Strategy UK Becomes First Major Economy to Pass Net Zero Emissions Law. Available online: https:/ / www.gov.uk/government/news/uk-becomes-first-major-economy-to-pass-net-zero-emissions-law (accessed on 1 August 2021).

4. The Parliamentary Office of Science and Technology Carbon Footprint of Heat Generation. Available online: http: / / researchbriefings.files.parliament.uk/documents/POST-PN-0523/POST-PN-0523.pdf (accessed on 28 May 2021).

5. Committee on Climate Change Reducing UK Emissions. Available online: https://www.theccc.org.uk/publication/reducing-ukemissions-2020-progress-report-to-parliament/ (accessed on 27 May 2021).

6. Cabeza, L.F.; Martorell, I.; Miró, L.; Fernández, A.I.; Barreneche, C. Introduction to thermal energy storage (TES) systems. In Advances in Thermal Energy Storage Systems; Woodhead Publishing Limited: Cambridge, UK, 2015; pp. 1-28. [CrossRef]

7. Zhao, B.C.; Li, T.X.; Gao, J.C.; Wang, R.Z. Latent heat thermal storage using salt hydrates for distributed building heating: A multi-level scale-up research. Renew. Sustain. Energy Rev. 2020, 121. [CrossRef]

8. Kerskes, H. Thermochemical Energy Storage. In Storing Energy: With Special Reference to Renewable Energy Sources; Elsevier Inc: Amsterdam, The Netherlands, 2016; pp. 345-372. [CrossRef]

9. Wu, S. Heat energy storage and cooling in buildings. In Materials for Energy Efficiency and Thermal Comfort in Buildings; Woodhead Publishing: New York, NY, USA, 2010; pp. 101-126. [CrossRef]

10. Englmair, G.; Moser, C.; Furbo, S.; Dannemand, M.; Fan, J. Design and functionality of a segmented heat-storage prototype utilizing stable supercooling of sodium acetate trihydrate in a solar heating system. Appl. Energy 2018, 221, 522-534. [CrossRef]

11. Dannemand, M.; Schultz, J.M.; Johansen, J.B.; Furbo, S. Long term thermal energy storage with stable supercooled sodium acetate trihydrate. Appl. Therm. Eng. 2015, 91, 671-678. [CrossRef]

12. Cabeza, L.F. Advances in thermal energy storage systems: Methods and applications. In Advances in Thermal Energy Storage Systems, 2nd ed.; Woodhead Publishing Limited: Cambridge, UK, 2021; pp. 37-54. [CrossRef]

13. Jungbluth, N. Life Cycle Inventory of Sodium Acetate and Expanded Graphite. Available online: https://www.osti.gov/ etdeweb/servlets/purl/22119615 (accessed on 18 June 2021). 
14. Noël, J.A.; Allred, P.M.; White, M.A. Life cycle assessment of two biologically produced phase change materials and their related products. Int. J. Life Cycle Assess. 2015, 20, 367-376. [CrossRef]

15. Lamnatou, C.; Notton, G.; Chemisana, D.; Cristofari, C. Storage systems for building-integrated photovoltaic (BIPV) and buildingintegrated photovoltaic/thermal (BIPVT) installations: Environmental profile and other aspects. Sci. Total Environ. 2020, 699, 134269. [CrossRef] [PubMed]

16. ISO. ISO 14044:2006 Environmental Management-Life Cycle Assessment-Requirements and Guidelines. Available online: https: / / www.iso.org/standard/38498.html (accessed on 1 September 2021).

17. ISO. ISO 14040:2006 Environmental Management-Life Cycle Assessment-Principles and Framework. Available online: https: //www.iso.org/standard/37456.html (accessed on 1 September 2021).

18. Oró, E.; Gil, A.; de Gracia, A.; Boer, D.; Cabeza, L.F. Comparative life cycle assessment of thermal energy storage systems for solar power plants. Renew. Energy 2012, 44, 166-173. [CrossRef]

19. Englmair, G.; Moser, C.; Schranzhofer, H.; Fan, J.; Furbo, S. A solar combi-system utilizing stable supercooling of sodium acetate trihydrate for heat storage: Numerical performance investigation. Appl. Energy 2019, 242, 1108-1120. [CrossRef]

20. Zhang, H. Heat-insulating Materials and Sound-absorbing Materials. Build. Mater. Civ. Eng. 2011, 316-423. [CrossRef]

21. Kingspan Solar Thermomax HP400 New Slimline Design Heat Pipe Vacuum Tube Solar Collector. Available online: https: / / www.midlandheating.ie/docs/solar-1-kingspan.pdf (accessed on 7 July 2021).

22. Armstrong Efficient Heat Transfer in a Compact Design. Available online: https://docplayer.net/27537357-Phe-plate-heatexchangers.html (accessed on 15 July 2020).

23. Tyfo TYCOR-LS. Available online: https://www.plumbase.co.uk/link/1/h030224_31294_t.pdf (accessed on 15 August 2021).

24. Ecoinvent Center the Ecoinvent Database. Available online: https://www.ecoinvent.org/database/database.html (accessed on 6 June 2021).

25. Federal LCA Commons USLCI Database. Available online: https://www.lcacommons.gov/lca-collaboration/search/page=1\& group=National_Renewable_Energy_Laboratory (accessed on 7 June 2021).

26. De Falco, M.; Capocelli, M.; Losito, G.; Piemonte, V. LCA perspective to assess the environmental impact of a novel PCM-based cold storage unit for the civil air conditioning. J. Clean. Prod. 2017, 165, 697-704. [CrossRef]

27. Adolfsson, M.; Rashid, S. Life Cycle Assessment and Life Cycle Cost of Heat Exchangers A Case for Inter Terminals Sweden AB Located in Port of Gothenburg. Master's Thesis, Chalmers University of Technology, Gothenburg, Sweden, 2016.

28. ACV Smart 600-Tank in Tank. Available online: https://www.acv.com/belgie/customer/product/06619301-393/smart-600 (accessed on 12 July 2020).

29. Complete Pumpsupplies Flamco Flexcon Premium 50 Litre Expansion Vessel. Available online: https: / www.completepumpsupplies. co.uk/flamco-flexcon-top-50-litre-expansion-vessel (accessed on 16 June 2021).

30. StoneMark Construction Management Pipes Are Not a Lifetime Component. Available online: https://stonemarkcm.com/blog/ pipes-not-lifetime-component/ (accessed on 5 August 2021).

31. EPA Table 1: Typical Equipment Life Expectancy. Available online: https://www.waterboards.ca.gov/drinking_water/certlic/ drinkingwater/documents/tmfplanningandreports/Typical_life.pdf (accessed on 21 July 2021).

32. Englmair, G.; Kong, W.; Brinkø Berg, J.; Furbo, S.; Fan, J. Demonstration of a solar combi-system utilizing stable supercooling of sodium acetate trihydrate for heat storage. Appl. Therm. Eng. 2020, 166, 114647. [CrossRef]

33. Masteel Applications of Grade 304 Stainless Steel. Available online: https://masteel.co.uk/type-304-stainless-steel/ (accessed on 2 July 2021).

34. Shah, K.N.; Varandani, N.S.; Panchani, M. Life Cycle Assessment of Household Water Tanks-A Study of LLDPE, Mild Steel and RCC Tanks. J. Environ. Prot. 2016, 7, 760-769. [CrossRef]

35. Plastics Europe. Plastics-The Facts 2019 an Analysis of European Plastics Production, Demand and Waste Data. Available online: https: / / www.plasticseurope.org/en/resources/market-data (accessed on 2 July 2021).

36. Bowyer, J.; Bratkovich, S.; Fernholz, K.; Frank, M.; Groot, H.; Howe, J.; Pepke, E. Understanding Steel Recovery and Recycling Rates and Limitations to Recycling; Dovetail Partners Inc.: Minneapolis, MN, USA, 2015; pp. 1-12.

37. Copper Alliance A Global View of Production and Trade. Available online: https://sustainablecopper.org/global-pathways/ (accessed on 15 August 2021).

38. OECD. OECD.stat. Available online: https://stats.oecd.org/\# (accessed on 28 July 2021).

39. Recovery Recycling Worldwide Glass Recycling-Current Market Trends. Available online: https: / www.recovery-worldwide. com/en/artikel/glass-recycling-current-market-trends_3248774.html (accessed on 20 June 2021).

40. Aste, N.; Groppi, F.; del Pero, C. The first installation under the Italian PV Rooftop Programme: A performance analysis referred to five years of operation. In Proceedings of the 2007 International Conference on Clean Electrical Power, Capri, Italy, 21-23 May; IEEE: Milan, Italy, 2007; pp. 360-365.

41. Bergsma, G.; Sevenster, M. End-of-Life Best Approach for Allocating Recycling Benefits in LCAs of Metal Packaging; CE Delft: Delft, The Netherlands, 2013; p. 25.

42. Gallego-Schmid, A.; Chen, H.-M.; Sharmina, M.; Mendoza, J.M.F. Links between circular economy and climate change mitigation in the built environment. J. Clean. Prod. 2020, 260, 121115. [CrossRef]

43. Heyes, G.; Sharmina, M.; Mendoza, J.M.F.; Gallego-Schmid, A.; Azapagic, A. Developing and implementing circular economy business models in service-oriented technology companies. J. Clean. Prod. 2018, 177, 621-632. [CrossRef] 
44. Mendoza, J.M.F.; Sharmina, M.; Gallego-Schmid, A.; Heyes, G.; Azapagic, A. Integrating Backcasting and Eco-Design for the Circular Economy: The BECE Framework. J. Ind. Ecol. 2017, 21, 526-544. [CrossRef]

45. Sansom, R. Decarbonising Low Grade Heat for Low Carbon Future. PhD. Thesis, Imperial College London, London, UK, 2014.

46. Huijbregts, M.A.J.; Steinmann, Z.J.N.; Elshout, P.M.F.; Stam, G.; Verones, F.; Vieira, M.; Zijp, M.; Hollander, A.; van Zelm, R. ReCiPe2016: A harmonised life cycle impact assessment method at midpoint and endpoint level. Int. J. Life Cycle Assess. 2017, 22, 138-147. [CrossRef]

47. Welfle, A.; Thornley, P.; Röder, M. A review of the role of bioenergy modelling in renewable energy research \& policy development. Biomass Bioenergy 2020, 136. [CrossRef]

48. Welfle, A.; Gilbert, P.; Thornley, P. Increasing biomass resource availability through supply chain analysis. Biomass Bioenergy 2014, 70, 249-266. [CrossRef]

49. Strbac, G.; Pudjianto, D.; Sansom, R.; Djapic, P.; Ameli, H.; Shah, N.; Brandon, N.; Hawkes, A. Analysis of Alternative UK Heat Decarbonisation Pathways. Available online: https://www.theccc.org.uk/wp-content/uploads/2018/06/Imperial-College-2018 -Analysis-of-Alternative-UK-Heat-Decarbonisation-Pathways.pdf (accessed on 29 July 2021). 